2016

\title{
Connecting Care in the Community: what works and what doesn't
}

Elizabeth Lucas

Grand Pacific Health, llucas@gph.org.au

Elizabeth J. Halcomb

University of Wollongong, ehalcomb@uow.edu.au

Sandra K. McCarthy

University of Wollongong

\section{Publication Details}

Lucas, E., Halcomb, E. \& McCarthy, S. (2016). Connecting Care in the Community: what works and what doesn't. Australian Journal of Primary Health, 22 539-544.

Research Online is the open access institutional repository for the University of Wollongong. For further information contact the UOW Library: research-pubs@uow.edu.au 


\title{
Connecting Care in the Community: what works and what doesn't
}

\begin{abstract}
As the burden of chronic and complex disease grows, there is an emphasis on programs that enhance the quality of care within primary care. The Connecting Care in the Community (CCC) program is an example of the implementation of care integration. This qualitative study sought to explore the experiences general practice staff face in managing clients with chronic and complex care issues, and their perceptions of the contribution of the CCC program to this care. Seventeen general practice staff from 11 practices throughout the Illawarra/Shoalhaven region participated in semistructured interviews. Five main themes emerged: (1) awareness of the CCC program; (2) varying program exposure and value placed on the program; (3) practice 'busyness' and role confusion; (4) communication and information sharing; and (5) the need for staff education and knowledge of local resources. If policymakers and healthcare organisations can gain a better understanding of the experiences of general practice staff, they will be able to design and implement programs that best meet the needs of the providers that they are attempting to integrate.
\end{abstract}

\author{
Disciplines \\ Medicine and Health Sciences | Social and Behavioral Sciences
}

\section{Publication Details}

Lucas, E., Halcomb, E. \& McCarthy, S. (2016). Connecting Care in the Community: what works and what doesn't. Australian Journal of Primary Health, 22 539-544. 
CONNECTING CARE IN THE COMMUNITY: WHAT WORKED AND WHAT

DIDN'T

\author{
A qualitative study exploring the general practice perception of the 'Connecting Care in the \\ Community' care coordination program.
}

Elizabeth Lucas ${ }^{\mathrm{A}, \mathrm{C}}$, Elizabeth Halcomb ${ }^{\mathrm{B}}$ and Sandra McCarthy ${ }^{\mathrm{A}}$

A Grand Pacific Health, PO Box 1198, Wollongong, NSW 2500, Australia.

B School of Nursing, Faculty of Science, Medicine and Health, University of Wollongong, Northfields Avenue, Wollongong, NSW 2522, Australia.

c Corresponding author. Email: $\underline{\text { lucas@gph.org.au }}$

\title{
What is known about this topic?
}

- The integration of care has the potential to improve outcomes for people with chronic disease, as well as optimise the utilisation of finite health resources.

\section{What does this paper add?}

- The success of care coordination programs is dependent upon a range of factors beyond the clinical efficacy of the intervention. Recognising and addressing these factors will enhance the uptake of these programs and allow better evaluation of their effectiveness.

\begin{abstract}
As the burden of chronic and complex disease grows there is an emphasis on programs which enhance the quality of care within primary care. The Connecting Care in the Community (CCC) program is one example of care integration that has been implemented. This qualitative study sought to explore the experiences general practice staff face in managing clients with chronic and complex care issues and their perceptions of the contribution of the CCC program to this care. Seventeen general practice staff from 11 Practices throughout the Illawarra/Shoalhaven region participated in semi-structured interviews. Five main themes emerged, namely; (1) Awareness of the CCC program, (2) varying program exposure and value placed on the program, (3) Practice 'busyness' and role confusion, (4) communication and information sharing, and (5) the need for staff education and knowledge of local resources. Better understanding the experiences of general practice staff will allow policy makers and health care organisations to design and
\end{abstract}


implement programs that best meet the needs of the providers that they are attempting to integrate.

\section{Introduction}

Chronic diseases account for an increasing proportion of healthcare expenditure and resources, contributing to more than $70 \%$ of the Australian disease burden (Australian Institute of Health and Welfare 2011). The growing burden of chronic disease is likely to intensify if hospital readmission rates rise due to less than optimal service integration in the community (NSW Agency for Clinical Innovation 2013). In 2013-14 it was estimated that $36 \%$ of general practice activity was generated by chronic conditions (Britt et al. 2014) and this burden is expected to rise as the population ages (Australian Institute of Health and Welfare 2011). It is generally accepted that the focus of contemporary healthcare needs to shift from episodic hospital care to ongoing primary care services that meet these challenging needs (Australian Government 2010). Consequently, the prevention and management of chronic disease has become a national health priority (National Health Priority Action Council 2006). Chronic diseases are best managed by integrated systems of care, with an emphasis on the primary health care sector (Wagner et al. 2001, IPART 2008). The integration of care and coordination of services enhances health outcomes and improves patient experiences, in addition to improving system level inefficiencies (Bywood et al. 2011). As a result, integrated health care has become an essential component of Australian health reform and one of the priority areas in the National Primary Health Care Strategy (Commonwealth of Australia 2010). It is these reforms that have set the scene for the development of the NSW Chronic Disease Management Program (NSW Health 2014).

The Connecting Care in the Community (CCC) program was initiated by NSW Health in 2010 in response to the Garling Enquiry (2008) and the National Health and Hospitals Reform Commission Report (2009). The program aims to unite GP, specialist medical, acute care and the community sector to provide patient-centred, team-based, coordinated care for patients enrolled in the program with one or more of the targeted chronic diseases; diabetes, chronic obstructive pulmonary disease, hypertension, coronary artery disease and congestive cardiac failure (Young 2013). CCC care coordinators work in consultation with GPs, consumers and other key providers and can be located in either Primary Health Care Organisations, General Practices or Local Health Districts (GP NSW 2013). Targeted enrolment underpins the program with real time identification of eligible patients on their third admission to hospital in a twelve month period. Additionally, 
referrals are received from health care professionals, community service providers and self-referrals (NSW Agency for Clinical Innovation 2013).

Extensive literature exists describing various models of care coordination, their implementation and patient outcomes (Teiman et al. 2007; McDonald et al. 2007; PowellDavies et al. 2008). However, there is limited evidence reporting on general practice perceptions and acceptance of these programs. Some evaluations of previous Australian chronic disease management programs have demonstrated varying levels of GP engagement (Bywood et al. 2011). Saunders (2011) suggested that the most successful models of care are those developed according to local need, providing local solutions. Learnings from the Victorian Integrated Disease Management Projects (Victorian Government 2005) recommend that GP engagement is crucial for the successful implementation of an integrated chronic disease program, suggesting that by understanding the GP perspective, resources can be more appropriately directed, enabling the development of a more robust primary healthcare system that is well equipped to meet changing demands.

A group led by the George Institute for Global Health was commissioned to conduct a state wide evaluation of the program. The primary objectives were to measure the impact, reach, equity and cost of the program. They concluded that there was great variation in the delivery of the program across sites, and overall the program fell short of an integrated approach to chronic disease management (NSW Health 2014). Given the variation in program delivery it is important to investigate local program to explore lessons that can be extrapolated to other sites. This paper reports on a qualitative study of general practice staff in a regional/rural region to explore their experiences of managing clients with chronic care issues and their perceptions of the contribution of the CCC program to this care.

\section{Methods}

Participant Recruitment

Purposive sampling was utilised to recruit practice staff including GPs, PNs, Practice Managers (PM) and allied health professionals from across the region. In addition to personal invitations, an expression of interest was included in the weekly newsletter distributed to all practices in the region via the Medicare Local over a four week period. Phone contact to confirm participation was made by the research officer who was independent of the CCC team. 44 invitations were sent to practice staff from 26 practices. 
These individuals and practices were chosen as they represented a diversity of rurality, practice size, socio-economic status and exposure to the CCC program.

\section{Interview process}

Individual face-to-face semi-structured interviews were conducted. Questions were designed to elicit data on the participants' experience and challenges when managing chronic and complex clients, in addition to their experience with the CCC program, including potential barriers and enablers towards integrating the program into usual practice.

Ethical approval was granted by the University of Wollongong and the Illawarra Shoalhaven Local Health District Human Research Ethics Committee (Approval No. HE13/481), and all participants provided written consent.

Interviews were conducted by a research officer and lasted between 20-40 minutes. Interviews were undertaken until data saturation had been reached, that is, no new information was being revealed in interviews. All interviews were audio taped and transcribed verbatim. De-identified transcripts were analysed using a process of thematic analysis (Braun \& Clarke, 2006). Each researcher read and re-read the transcripts to immerse themselves in the data and created initial codes. The team then came together to search for themes. Through discussion the themes were identified and refined before being named and the findings produced.

Figure 1. Interview Schedule

1. Can you tell me what your experience of managing patients with chronic and complex conditions has been?

2. What challenges have you faced when managing this patient group?

3. Can you tell me what your experience has been with the CCC program?

4. Can you give me an example of how the CCC program has benefited your patients?

5. Can you give me an example of when enrolment in the CCC program has not worked well for either the patient or the Practice?

6. What do you consider to be the strengths of the CCC program?

7. What do you consider to be the weaknesses of the CCC program?

8. Are you satisfied with the level of communication between CCC staff and the Practice? Can you provide examples of this?

9. What do you consider to be barriers towards referral to the CCC program?

10. What do you consider to be enablers towards referral to the CCC program?

11. What do you see as the barriers to integrating this program into usual care?

12. What factors will assist in integrating the $\mathrm{CCC}$ program into usual care? 


\section{Results}

Interviews were conducted with 17 general practice staff from 11 practices, including 3 GPs, 10 PNs, 3 PMs and an allied health professional. A diverse range of practices were represented including both large and small practices, and practices with varying degrees of previous involvement with the CCC program. Most participating practices were located in urban areas ( $n=8 ; 73 \%$ ). Five main themes emerged, namely; (1) Awareness of the Connecting Care in the Community program, (2) Varying program exposure and value placed on the program, (3) Practice 'busyness' and role confusion, (4) Communication and information sharing, and (5) The need for staff education and knowledge of local resources. Each of these is described in turn below.

\section{Awareness of the Connecting Care in the Community Program}

Varying levels of exposure to the CCC program, and therefore knowledge and awareness of the program were voiced by participants. Many responses demonstrated limited knowledge about the program, its inclusion criteria, referral process and the benefits of the program. "I don't think that it's been as well utilised as it could be in this practice...I think that I actually need to be refreshed on how to go about referring" (GP1). Others also conceded that their understanding of the program was sub-optimal. "I might have had experience with it but I'm not aware" (GP1), and "I have an understanding that it is there in place. As far as anything past that, I don't know" (PN2).

However, some PNs championed the program and were far more familiar with it having utilised it for their patients and reported "It's a very good idea...we've probably had about a dozen patients referred to it" (PN1), with another PN stating "We've been able to utilise the program for some of our patients... we also see responses coming back, patients who have been referred by the hospital" (PN1).

All participants voiced the need for more education and exposure to the CCC program with the preference overwhelmingly being for face to face contact from the CCC coordinator. "They can send out as much information as they like but it needs to be face to face" (PM1), and "I think what I find most helpful is actual face-to-face contact with someone who's involved in the program, and it's better for us as a Practice, in a group setting" (GP1).

\section{Varying program exposure and value placed on it}

Several participants voiced frustration and dissatisfaction with the inclusion criteria for the CCC program, considering that it should have incorporated other chronic diseases such as multiple sclerosis and musculoskeletal conditions. "I do wonder if the scope could be a 
little wider, not limited to those conditions. People are in great need" (PN1). "One of the problems is the restriction of diagnoses for who can use the program. I don't quite understand why it's restricted to certain diseases" (PN1).

Interestingly, even with limited knowledge and exposure to the program, all participants viewed it positively, recognising the benefit to the patient. "It seems a useful program, but I haven't really had the opportunity to implement it for anyone" (GP1), with another GP from a larger practice stating "I think its brought them (patients) back to my attention, it's benefited them as we have over 9000 patients on the books at the moment" (GP1).

GPs in particular reflected upon the assortment of available programs for their patients, noting how confusing this can become. One GP said "The problem for me is that there are so many different programs, organisations and referral pathways for patients, it's hard to keep track of what's available for each individual" (GP1). A number of PNs, however, had a lot of experience with the program stating "The program has really helped with those patients who are far more challenging... because the CCC coordinator has a broader knowledge of what's out there" (PN1). This tended to be from smaller practices where individual practice staff had developed a relationship with the CCC coordinator and used the program regularly claiming "I think it's a great resource to have... it might be easier to achieve in smaller practices where one person is responsible for the program" (PN1).

\section{Practice 'busyness' and role confusion}

Most participants made reference to how busy the general practice environment is, especially for the GP, citing lack of time as the biggest barrier to delivering quality care. "Once again just time, that's the biggest barrier" (PN1), and "It's hard to keep track of what's happening with them (patients), the doctors are just so busy" (PM1). Another PN reinforced this stating that her biggest challenge was "having enough time and resources to be able to allocate time to do all these things" (PN1).

The subject of practice busyness sanctioned discussion by participants relating to role clarification, challenging participants to consider who within the practice was best placed to coordinate CDM and ensure appropriate referrals to complementary programs and services. There were several PN champions who were responsible for CDM in their practice, and these PNs were actively engaged with the CCC program, however for most, it was unclear whose responsibility it should be.

One GP suggested that the PNs would be the best ones to assume this responsibility stating that "It could definitely be done by the nurses as they do most of our chronic disease management plans, referrals and home health assessments" (GP1). Most of the 
PNs agreed with this option, remarking that a strength of the PN role was the ability to educate patients and refer them to community services, "While I'm doing care plans I can identify some patients and suggest this to the doctors" (PN1). They recognised the role the nurse could play in referrals stating "I think it's good when it's coming through the nurses within the practice...so if we're aware of programs, we can promote them" (PN1).

\section{Communication and information sharing}

The level of communication between the $\mathrm{CCC}$ coordinators and practices varied significantly. Some were quite vague about this "I'm pretty sure we got a letter back, a summary letter from Connecting Care' (PN1), and "They sent us stuff here, we get emails and advice" (GP1), whereas other PNs reported "We never get feedback.....as far as one on one phone calls yes, but probably we're not getting a lot of written communication" (PN1). This was in contrast to the PN champions who reported that "we can call them anytime, or we can send an email and they'll get back to us every time" (PN1).

This highlighted some issues with communication systems within practices. One PN recalled receiving written correspondence but said "I'm pretty sure we get summary letters back from Connecting Care...I haven't read those letters...it's almost impossible in general practice for all the letters to come via the GP and then get sent through to the nurses" (PN1), adding "There might be four or five nurses, you can't get everybody to see everything that comes back that's relevant to the nurses". The sharing of information was also raised as an issue with one PN commenting that "One of the problems that I have found in practice nursing is that sometimes you'll get a flyer...and whoever's on duty reads it....and sometimes that's the only person in the practice that sees it. We try and share things here but it doesn't always happen that way.... if you get busy" (PN1).

\section{The need for staff education and knowledge of local resources.}

All PN participants expressed a need for ongoing education on subjects related to chronic disease management, advocating for the valuable role that PNs play in patient education. One PN said "for the nurses, I think having education in all these different areas is needed" (PN1). Another PN suggested that nurses need "better education...in general, on what we should be providing to the patients", acknowledging that "not everyone shares their information....and sometimes you don't have a mentor or experienced nurse that you can ask" (PN1).

A lack of awareness of the array of services that are available for their patients was identified by many participants. The issue is "just knowing what services are available, sometimes you're not even particularly sure yourself" (PN2), adding that "you've got to 
have the time to do it as well". This theme was reinforced by others who stated "I'd love to have some sort of summary of what is available and who does what when" (PN1), in addition to "knowing what services are available, a good comprehensive list of what is in the local area, and how we can get patients there because you don't always know what the best options are".

\section{Discussion}

This paper has provided an overview of the challenges faced by general practice staff in managing chronic and complex disease and working with the $\mathrm{CCC}$ program. It has highlighted the busyness of the general practice setting and the high number of competing priorities facing clinicians. A key danger identified by participants is that the growing plethora of programs designed to integrate and improve CDM can actually impede clinical care as clinicians are left to navigate the maze of services on offer. Despite the clear benefits of research in informing the implementation of these kinds of programs (May et al, 2010), our data revealed limited evidence of strategies aimed to facilitate program implementation. Future programs should include not only evidence based clinical interventions to improve health outcomes but also be accompanied by evidence based implementation strategies to ensure that these programs become embedded within usual care (May et al, 2010). Without this implementation support any program, regardless of its efficacy, is destined to not reach its potential in terms of engagement and uptake.

Whilst care coordination has been demonstrated to improve outcomes in a range of chronic diseases (Bywood et al. 2011), discussion of formal coordination of care was largely absent from participants' responses. This highlights some of the challenges about how health professionals work together in Australian general practice (Mclnnes et al., 2015). Although some nurse participants reportedly took on a level of responsibility for CDM, particularly in terms of care planning, the exact nature of their role and coordination with general practitioners and other general practice staff was unclear. This lack of clarity around roles within the general practice team has the potential to lead to role confusion and ambiguity (Oandasen et al. 1010, Moaveni et al. 2010, Mclnnes et al. 2015). This, in turn, can have a negative impact on job satisfaction and retention of staff (Smith, 2011). Aside from the workforce implications, role confusion can impact on the timely and quality delivery of health services and patient health outcomes. Given the rapid expansion of the nursing workforce in Australian general practice such role confusion is not surprising (McInnes et al, 2015). However, future work needs to focus on ensuring that health 
professionals, particularly in general practice have clearly defined roles and responsibilities and share an understanding of each other's scope of practice. The importance of conversations between health professionals about the nature of their role and their scope of their practice cannot be underestimated in setting the scene for mutual understanding.

Our study highlighted a lack of teamwork and impaired delivery of information between staff within Practices. Such an issue is not unique, in their integrated review of teamwork in general practice McInnes et al. (2015) identified a lack of communication between GPs and nurses in general practice. Given that CDM has been shown to be best delivered by integrated multidisciplinary teams (Wagner et al. 2001), further attention needs to be paid to the health professionals within general practices and they ways in which they work. Developing strategies to optimise effective communication within Practices is essential if we are to achieve gains with any models that integrate Practices with the broader health system. Given the substantial differences between individual general practices, perhaps the first step to achieving such improvements is for practice staff to critically reflect on current ways of working and assess how well they meet the needs of staff and consumers.

\section{Limitations}

The limitations of our study are related to the relatively small sample size and the fact that participants were located in a single geographical area. However, this area is rich in demographic and socio-economic diversity and comprised two centres running the CCC program in different locations. Evaluation of other instances of the CCC program may provide different insights. A further limitation is that there is a potential risk of response bias. Individuals who were more likely to respond may have been those with either strongly positive or negative experiences or an association with the researchers. Despite these limitations we believe that our study provides an important insight into the implementation of this program and the way it is perceived by clinicians in general practice.

\section{Implications for policy}

Interventions such as the CCC program, which provide a Nurse Coordinator to facilitate service integration, have significant potential to improve both clinical processes and health outcomes. However, at a policy level the boundaries between various health 
service providers and the complexities of intersectorial collaboration need to not be underestimated. Future policy needs to consider this complexity in the development of its programs and provide sufficient resources to enable strategies to assist in embedding interventions into the context in which they are being delivered.

\section{Implications for practice}

This study highlights some of the key challenges in implementing interventions in Australian general practice. In particular, the role confusion between general practitioners and general practice nurses and the impact of time constraints and workload have been demonstrated to impact on the uptake of the CCC program. Additionally, the impact of a paucity of opportunities for interdisciplinary education and knowledge sharing are highlighted. Improved communication between practice staff themselves and between practice staff and CCC staff would likely improve the interface between these two groups.

\section{Implications for research}

Further research is required to evaluate other aspects of the CCC program and test innovative strategies to enhance uptake of the program and address some of the key issues raised by this study. Future research needs to focus more explicitly on how interventions, such as the CCC program, can be better embedded within the clinical service delivery of general practice.

\section{Conclusion}

This paper has demonstrated that despite the emphasis placed on CDM programs in primary care there is still significant work to do in order to achieve integrated care models. Developing a better understanding of the experiences of general practice staff will allow policy makers and health care organisations to design and implement programs that best meet the needs of the providers that they are attempting to integrate. 


\section{Conflict of Interest}

Nil

\section{Acknowledgements}

Connecting Care in the Community (CDMP) is funded by the Illawarra Shoalhaven Local Health District. The researchers would like to acknowledge the financial contribution of the Agency for Clinical Innovation (ACl), which funded the activities outlined in this paper through an Innovative Primary Health Initiatives grant. 


\section{References}

Australian Government 2010, A National Health and Hospitals Network for Australia's

future: Delivering the reforms, retrieved from http://www.yourhealth.gov.au/internet/yourHealth/publishing.nsf/Content/DeliveringTheRef orms/\$FILE/DeliveringTheReforms.pdf

Australian Institute of Health and Welfare 20011, 'Health Expenditure Australia 2009-10, no. 46.' (AlHW: Canberra) Australian Institute of Health and Welfare, Canberra Independent Pricing and Regulatory Tribunal of NSW (IPART), Framework for Performance Improvement in Health, September 2008.

Braun, V. \& Clarke, V. 2006. Using thematic analysis in psychology. Qualitative Research in Psychology, 3, 77-101.

Britt, H, Miller, G, Henderson, J, Bayram, C, Harrison, C, Valenti, L, Wong, C, Gordon, J 2014, General practice activity in Australia 2013-14, General practice series no. 36, Sydney University Press, Sydney, NSW.

Bywood, P, Jackson-Bowers, E \& Muecke, S 2011, Initiatives to integrate primary and acute health care, including ambulatory care services, PHC RIS Policy Issue Review, Adelaide: Primary Health Care Research \& Information Service.

Commonwealth of Australia 2010, Building a $21^{\text {st }}$ Century Primary Health Care, Australia's First National Primary Health Care Strategy, Australian Government, Canberra.

Curry, N \& Ham, C 2010, Clinical and Service Integration: The Route to Improved Outcomes, The King's Fund, London, UK.

Dunbar, J \& Reddy, P 2009, 'Integration and coordination of care', Australian Journal of Rural Health, vol. 17, no. 1, pp. 27-33.

Ehrlich, C, Kendall, E, Muenchberger, H \& Armstrong, K 2009, 'Coordinated care: what does it really mean?', Health and Social Care in the Community' vol. 17, no. 6, pp. 619627.

Garling, P 2008, Final Report of the Special Commission of Inquiry Acute Care Services in NSW Public Hospitals, NSW Government, Sydney. 
GP NSW 2013, 'NSW Health Chronic Disease Management - Connecting Care in the Community Program (CDMP), retrieved from http://www.gpnsw.com.au accessed 1 October 2013.

Greb, S, Baan, C, Calnan, M, Dedeu, T, Goenewegan, P, Howsan, H, Maroy, L, Nolte, E, Redaelli, M, Saarelma, O, Schmackee, N, Schumacher, K, van Lente, E \& Vrighoef, B 2009, 'Coordination and management of chronic conditions in Europe: the role of primary care - position paper of the European Forum of Primary Care', Quality in Primary Care, vol. 17 , pp. $75-86$.

McDonald, K, Sundaram, V, Bravata, D, Lewis, R, Lin, N, Kraft, S, McKinnon, M, Paguntalan, H \& Owens, D 2007, 'Closing the quality gap: a critical analysis of quality improvement strategies, vol. 7: Care coordination', (Technical review no. 9), retrieved from http//www.ahrq.gov/downloads/pub/evidence/pdf/caregap/caregap.pdf

Mclnnes, S., Peters, K., Bonney, A., \& Halcomb, E. (2015). An integrative review of facilitators and barriers influencing collaboration and teamwork between general practitioners and nurses working in general practice. Journal of Advanced Nursing, 71(9), 1973-1985. doi: 10.1111/jan.12647

May, C., Murray, E., Finch, T., Mair, F., Treweek, S., Ballini, L., Macfarlane, A. and Rapley, T. Normalization Process Theory On-line Users' Manual and Toolkit 2010 [cited 2015 February 11th]; Available from: http://www.normalizationprocess.org.

Moaveni, A., Gallinaro, A., Conn, L.G., et al. A Delphi approach to developing a core competency framework for family practice registered nurses in Ontario. Nursing Leadership (Toronto, Ont.), 2010. 23(4): p. 45-60.

National Health and Hospitals Reform Commission, $A$ healthier future for all Australians: final report June 2009, Report No. P3-5499, Canberra, 2009.

National Health Priority Action Council 2006, National Chronic Disease Strategy, Australian Government Department of Health and Ageing: Canberra.

NSW Agency for Clinical Innovation 2013, NSW Chronic Disease Management ProgramConnecting Care in the Community, Service Model 2013, Sydney. 
NSW Health 2014, State-wide evaluation NSW Health Chronic Disease Management Program, Final Report, October 2014, Sydney.

Oandasan, I.F., Hammond, M., Conn, L.G., et al. Family practice registered nurses: The time has come. Canadian Family Physician, 2010. 56(10): p. e375-82.

Oliver-Baxter, J, Brown, L, O'Connor, J, Lunnay, B \& Bywood, P 2013, 'Integrated care: What can be done at the micro level to influence integration in primary health care?' PHCRIS Policy Issue Review, Primary Health Care Research \& Information Service, Adelaide.

Powell-Davies, G, Williams, A, Larsen, K, Perkins, D, Roland, M \& Harris, M 2008, 'Coordinating primary healthcare: an analysis of the outcomes of a systematic review', Medical Journal of Australia, vol. 188, no. 8, pp. S65-S68.

Rodwell, J \& Gulyas, A 2013, 'The variety of primary healthcare organisations in Australia: a taxonomy', BMC Health Services Research, vol. 13, no. 130, retrieved from http://biomedcentral.com/1472-6963/13/130

Saunders, C 2011, Chronic Disease Management in Primary Care, GP NSW, Sydney.

Smith AC (2011): Role Ambiguity and Role Conflict in Nurse Case Managers: An Integrative Review. Professional Case Management 16, 182-196.

Teiman, J, Mitchell, G \& Shelby-James, T 2007, 'Integration, coordination and multidisciplinary care: what can these approaches offer to Australian primary healthcare?', Australian Journal of Primary Health, vol. 13, pp. 56-65.

Victorian Government 2005, 'Improving chronic disease care: Learnings from the Integrated disease management projects, October 2005, retrieved from http://www.health.victoria.gov.au/pcps/publications/index.htm

Wagner, EH, Austin, BT, Davis, C, Hindmarsh, M, Schaefer, J \& Bonomi, A 2001 Improving chronic illness care: translating evidence into action. . Health Aff (Millwood), vol. 20, no. 6, Nov-Dec, pp. 64-78 
Young, K 2013, The NSW Health Chronic Disease Management - Connecting Care in the Community program (CDMP): Program overview and discussion paper, last updated 21/03/2013, GP NSW, Sydney. 